\title{
Desenvolvimento, Validação e Aplicação Piloto do Sistema de Observação da Instrução do Instrutor de Fitness em Aulas de Pilates
}

\author{
Development, Validation, and Pilot Application of the Instruction \\ Observation System used by Fitness instructors in Pilates Classes.
}

\section{Desarrollo, Validación y Aplicación Piloto del Sistema de Observación de la Instrucción del Instructor de Fitness en Clases de Pilates}

\author{
Luís, $T^{1}$, Simões, $\mathrm{V}^{1,2}$, Ramos, $\mathrm{L}^{1,2}$, Franco, $\mathrm{S}^{1,2}$. \\ ${ }^{1}$ Escola Superior de Desporto de Rio Maior - Instituto Politécnico de Santarém; \\ ${ }^{2}$ Centro de Investigação em Qualidade de Vida (CIEQV)
}

Fontes de financiamento: Fundação para a Ciência e a Tecnologia, I.P., Projeto No UIDP/04748/2020

\begin{abstract}
RESUMO
Considerando as especificidades e princípios do método Pilates, o presente estudo tem como objetivo desenvolver e validar um sistema de observação que permita observar os comportamentos de instrução dos técnicos de exercício físico na atividade de Pilates, (SOIIF-PILATES), a partir da adaptação de um instrumento já existente. Após diversos procedimentos metodológicos para testar a funcionalidade do instrumento, o SOIIF-PILATES demonstrou apresentar validade e fiabilidade, sendo constituído por 2 dois critérios/dimensões (momento e conteúdo) e 15 categorias. Foi também realizada uma aplicação piloto do instrumento numa amostra de 15 técnicos de exercício físico na atividade de Pilates que permitiu caracterizar a sua intervenção assim como compará-la relativamente às fases da aula (aquecimento, parte fundamental e relaxamento/alongamento) e do exercício (antes, durante e após o exercício). Os resultados do estudo piloto demonstraram que a maioria das categorias referidas pelos técnicos de exercício físico estão de acordo com os princípios da modalidade de Pilates, o que pode justificar a sua elevada utilização. Foram encontradas diferenças no total da instrução nas diferentes fases da aula e entre as diferentes fases da aula e do exercício.
\end{abstract}

Palavras-chave: observação, instrução, Fitness, Pilates. 


\title{
Luís, T, Simões, V, Ramos, L, Franco, S.
}

\begin{abstract}
Considering the specificities and principles of the Pilates method, the present study aims to develop and validate an observation system that allows us to observe the instructional behaviors of Fitness instructors in the Pilates activity (SOIIF-PILATES), based on the adaptation of an instrument that already exist. After several methodological procedures to test the functionality of the instrument, the SOIIF-PILATES proved to be valid and reliable, consisting of two dimensions (moment and content) and 15 categories. A pilot application of the instrument was also carried out in a sample of 15 Fitness instructors of the Pilates activity, which allowed to characterize their intervention as well as to compare it in different phases of the class (warm-up, main part and relaxation/stretching) and in different parts of the exercise (before, during and after the exercise) The results of the pilot study reveal that most of the categories referred by the instructors are following the principles of Pilates, which may justify their high utilization. Differences were found in the total of instruction of the different phases of the class and between the different phases of the class and the different phases of the exercise.
\end{abstract}

Keywords: observation, instruction, Fitness, Pilates.

\section{RESUMEN}

Considerando las especificidades y principios del método Pilates, el presente estudio tiene como objetivo desarrollar y validar un sistema de observación que permita observar los comportamientos de instrucción de instructores de Fitness en la actividad Pilates, (SOIIF-PILATES), a partir de la adaptación de un instrumento ya existente. Después de varios procedimientos metodológicos para probar la funcionalidad del instrumento, el SOIIF-PILATES creado demostró presentar validez y fiabilidad siendo constituido por dos criterios/dimensiones (momento y contenido) y 15 categorías. Se realizó también una aplicación piloto del instrumento en una muestra de 15 instructores en la actividad de Pilates que permitió caracterizar su intervención, así como compararla con las fases de la clase (calentamiento, parte fundamental y relajación/estiramiento) y del ejercicio (antes, durante y después del ejercicio). Los resultados del estudio piloto demostraron que la mayoría de las categorías mencionadas por las instructoras se ajusta a los principios de Pilates, lo que puede justificar su elevada utilización. Se encontraron diferencias en el total de la instrucción en las diferentes fases de la clase y entre las diferentes fases de la clase y el ejercicio.

Palabras clave: observación, instrucción, Fitness, Pilates

\section{INTRODUÇÃO}

Durante os últimos 30 anos a indústria do Fitness provou ser dinâmica, continuando a crescer e a adaptar-se continuamente às necessidades dos seus consumidores (IHRSA, 2016). Com esse aumento e com a exigência e elevada concorrência entre os serviços existentes, uma das preocupações de gestão do mundo do Fitness é a prestação de um serviço de qualidade, que leve à satisfação, motivação e retenção dos seus praticantes, tendo os instrutores $\mathrm{e}$ as interações sociais que se criam um papel muito importante neste sentido (Papadimitriou \& Karteroliotis, 2000; Rodrigues et al., 2018; Rosa et al., 2015).

Rodrigues (2000) considera cinco dimensões como sendo as principais funções pedagógicas de um treinador, sendo estas, a instrução, a organização, a interação, o controlo e a atividade. A instrução referese às situações de comunicação das tarefas, como seja a informação e a demonstração, ao questionamento e às situações de feedback acerca das tarefas realizadas pelos praticantes, através de correção, da avaliação positiva e da avaliação negativa. Relativamente à instrução Franco, Rodrigues e Balcells (2008), num estudo realizado em aulas de grupo de Fitness de Localizada, constatou que na maioria do tempo da aula $(59.8 \%)$ os técnicos de exercício físico (TEFs) encontram-se a realizar comportamentos de instrução, seguindo-se comportamentos de controlo (27.6\%), particularmente de observação (26.8\%). Neste estudo verificou-se ainda que a duração da informação com exercício, que é apresentada enquanto o técnico de exercício físico (TEF) está a realizar exercício 


\section{Desenvolvimento, Validação e Aplicação Piloto do SOIIF-Pilates}

juntamente com os praticantes, foi quase 10 vezes superior à demonstração com informação, que é apresentada previamente aos praticantes, e que a informação apresentou valores superiores à correção, denotando que poderá ser estratégico ir continuando a explicação dos exercícios durante a realização dos mesmos pelos praticantes como estratégia de rentabilização do tempo de prática e de evitar correções. Em diversas atividades de grupo de Fitness, nomeadamente, Zumba ${ }^{\circledR}$, Localizada e Indoor Cycling, verificou-se que os comportamentos de instrução são dos mais preferidos pelos praticantes (Franco, Mercê \& Simões, 2015; Franco, Rodrigues \& Castañer, 2012; Mercê, Franco, Alves, Campos, \& Simões, 2015), reforçando assim a sua importância. A falta de explicação das habilidades motoras poderá levar a que os praticantes não consigam realizar o que lhes é proposto, sentindo-se com falta de competência, o que pode trazer consequências na sua motivação intrínseca e adesão (Rodrigues et al., 2018). Acrescenta-se ainda que no estudo de Franco et al. (2012) a informação, explicando ou relembrando o modo de executar os exercícios, estando ou não o TEF a realizar o mesmo exercício que os praticantes, encontra-se relacionada positivamente com o nível de satisfação dos praticantes.

O comportamento pedagógico dos TEFs tem vindo a ser uma preocupação por parte de vários investigadores, tal como mencionado numa revisão sistemática recentemente desenvolvida por Rodrigues et al. (2018). Neste sentido, alguns instrumentos têm vindo a ser desenvolvidos no contexto do Fitness nomeadamente: o Sistema de Observação do Comportamento dos Instrutores de Fitness (SOCIF), adaptado por Franco et al. (2008), que permite codificar os comportamentos nas principais funções pedagógicas dos TEFs em aulas de grupo; o Sistema de Observação de Feedback de Instrutores de Fitness em Aulas de Grupo (SOFIF-AG), desenvolvido por Franco e Simões (2017), que permite analisar o comportamento de feedback realizado pelos TEFs de aulas de grupo; o Sistema de Observação do Clima de Aulas de Grupo de Fitness (SOCA-AGF), validado por Dias, Franco, Ramos e Simões (2020), que permite analisar o clima numa aula de grupo, o Sistema de Observação da Comunicação Proxémica do Instrutor de Fitness em Aulas de Grupo (SOPROX- Fitness), de Alves et al. (2013), que permite analisar a comunicação proxémica dos TEFs nas aulas de grupo; e o Sistema de Observação da Comunicação Cinésia
(SOCIN- Fitness), desenvolvido por Alves et al. (2014), que permite analisar a comunicação cinésia dos TEFs em aulas de grupo. No que diz respeito ao comportamento de instrução foi encontrado um instrumento de observação denominado Sistema de Apreciação da Qualidade e Pertinência da Informação (SAQPI), desenvolvido por Sarmento, Veiga, Rosado e Ferreira (1998), para o contexto de educação física, que tem como objetivo apreciar a qualidade formal e de conteúdo dos momentos de informação, através da análise de fatores determinantes da veiculação da informação e de organização estrutural da mensagem, utilizáveis quando existisse introdução de novos conteúdos, apresentação de tarefas ou exercícios, particularmente no início, no decorrer e no encerramento da aula. Os comportamentos são, neste sistema, codificados utilizando uma escala de apreciação de sim ou não para cada um dos episódios de informação. Este é constituído por três critérios/dimensões de análise, compostas por 15 categorias. Também dos mesmos autores existe o Sistema de Observação da Qualidade das Preleções (SOQP) o qual aprecia a qualidade formal e de conteúdo dos momentos de informação utilizados pelos professores de educação física e permite a medição da duração dos diversos episódios de preleção da sessão. Embora estes instrumentos abordem comportamentos de instrução, estes estão direcionados para as aulas de educação física escolar, não estando direcionados para o contexto de aulas de grupo de Fitness. Realça-se a importância de desenvolver sistemas de observação ad hoc, adaptados ao contexto a observar (Anguera \& HernándezMendo, 2013).

O método Pilates teve uma elevada expansão nos últimos anos, aumentando substancialmente o número de praticantes (Isacowitz \& Clippinger, 2011). Pilates é um tipo de exercício de corpo e mente (mind\&body) focado na força, estabilidade do core, flexibilidade, controlo muscular, postura e respiração. Os exercícios podem ser realizados no chão apenas com o auxílio de um colchão, o chamado Pilates-Matwork (Pilates-Mat) ou envolvendo o uso de equipamentos específicos (Wells, Kolt, \& Biolocerlowski, 2020). Matos (2011) menciona o método Pilates como um programa de treino de relaxamento, vitalização e fortalecimento do corpo, mente e espírito, com uma respiração controlada, movimentos fluidos e o fortalecimento dos grupos musculares mais profundos. Os benefícios, físicos e psicológicos, da prática de Pilates têm vindo 
a ser expostos, ao longo dos anos, pela comunidade científica. Alguns destes benefícios surgem associados à diminuição da dor lombar, aumento da flexibilidade e força, bem como melhorar a qualidade de vida e diminuição do medo de praticar exercício físico (Bem, Tavares, \& Vendrusculo, 2019), a melhoria nas lombalgias e capacidade de realizar tarefas de vida diária em mulheres dos 40 aos 60 anos (Vecchi, Minasi, \& Nora, 2015), o tratamento da dor lombar crónica (Souza, Justo, Silva, Lazzareschi, \& Glória, 2019), a melhoria da resistência muscular, flexibilidade e equilíbrio de mulheres jovens (Oliveira et al., 2014), a melhoria da performance em atletas de diferentes modalidades desportivas (Abreu, Santos, Nogueira, Zampeiri, \& Bertoncellona, 2020) e a qualidade do sono em adultos e idosos (Filho et al., 2019), entre outros. Muscolino e Cipriani (2004) referem que este método apresenta seis princípios fundamentais, sendo eles: centralização, concentração, repetições dos exercícios, precisão, respiração e fluidez de movimento. A existência destes princípios faz com que a instrução por parte dos TEFs tenha de ser efetiva, assumindo um papel preponderante para o sucesso dos praticantes na modalidade.

Neste sentido e tendo em conta que nenhum dos instrumentos de observação sistemática encontrados na literatura dava resposta às especificidades da instrução no método Pilates, o principal objetivo do estudo prende-se com desenvolver e validar um sistema de observação que permita codificar os comportamentos da instrução dos TEFs na atividade de Pilates (SOIIF-PILATES). Decorrente do processo de desenvolvimento da validação do SOIIF-PILATES foi realizada uma aplicação piloto do SOIIF-PILATES para testar a sua funcionalidade, permitindo também caracterizar a instrução dos TEFs na atividade de Pilates assim como compará-la nas diferentes fases da aula (aquecimento, parte fundamental e relaxamento/alongamento) e de realização do exercício (antes, durante e após o exercício), constituindo-se esse como segundo objetivo deste estudo.

\section{MATERIAL E MÉTODOS}

Desenvolvimento e Validação do SOIIF-PILATES. O desenho observacional do presente estudo relativamente à temporalidade de registo é pontual, quanto às unidades observadas é ideográfico e quanto à dimensionalidade é multidimensional (Anguera, Blanco \& Losada, 2001; Anguera \& HernándezMendo, 2013; Blanco, Losada \& Anguera, 2003).

Para desenvolver e validar o SOIIF-PILATES, foram seguidos os pressupostos recomendados por diversos autores. Assim sendo, para o desenvolvimento e validação do sistema de observação SOIIF-PILATES, partiu-se do Sistema de Apreciação da Qualidade e Pertinência da Informação (Sarmento et al., 1998). O desenvolvimento e validação do SOIIF-PILATES foi realizado de acordo com cinco fases, descritas de seguida e propostas na metodologia de Brewer e Jones (2002), as quais têm sido aplicadas no desenvolvimento e validação de sistemas de observação no contexto desportivo e particularmente também, no contexto do Fitness (Alves et al., 2013; Alves et al., 2014, Dias, Franco, Ramos \& Simões, 2020; Franco et al., 2008; Franco e Simões, 2017).

No desenvolvimento do SOIIF-PILATES optou-se por um sistema misto de formatos de campo e categorias tal como em vários estudos de observação relacionados com a área do desporto (Anguera, 2003; Anguera \& Blanco, 2003, 2005; Anguera, Magnusson \& Jonsson, 2007; Anguera \& Hernández-Mendo, 2013). Seguidamente ao desenvolvimento e validação do sistema foi realizada a aplicação piloto do mesmo, permitindo testar a sua funcionalidade.

\section{Fase 1: Treino dos observadores relativamente ao sistema de observação original}

Com o objetivo de assegurar que quem vai desenvolver o sistema conhece o instrumento existente na totalidade, assim como compreende todas as suas terminologias, conceitos, procedimentos e metodologias, foi realizado o treino de observação, obedecendo às fases sugeridas por Carreiro da Costa (1998), Mars (1989) e Rodrigues (1997), nomeadamente a identificação das categorias do sistema, a discussão do protocolo de observação, a avaliação da aprendizagem das categorias e a prática e aplicação do sistema de observação.

Fase 2: Adaptação do instrumento já existente para o contexto das aulas de Pilates

Já foi referida, anteriormente, a necessidade de desenvolver sistemas de observação $a d$ hoc, adaptados 


\section{Desenvolvimento, Validação e Aplicação Piloto do SOIIF-Pilates}

ao contexto a observar (Anguera \& HernándezMendo, 2013). A fim de respeitar a validade de conteúdo e segundo as recomendações de Alexandre e Coluci (2011), foi convidado um painel de três especialistas. Após a sua concordância, foi criado o primeiro painel para que fosse realizado $o$ desenvolvimento de um novo sistema recorrendo à literatura existente e à observação de várias aulas de Pilates. Este painel foi integrado por um grupo de sujeitos ligados à intervenção e formação profissional na área das aulas de grupo no contexto do Fitness, particularmente também em Pilates e que possuíssem também competências na área da investigação na intervenção pedagógica em aulas de grupo de Fitness e no desporto em geral, assim como no desenvolvimento e utilização de sistemas de observação. O referido painel de especialistas efetuou uma análise da bibliografia encontrada relativamente à utilização de critérios/dimensões e categorias de análise do comportamento de instrução nos vários contextos (educação física e ensino). Posteriormente, para o desenvolvimento do sistema de observação, o painel realizou várias observações piloto de diferentes aulas de Pilates. Após uma análise sobre a utilização de sistemas de observação e estudos que contemplem o conceito de comportamento de instrução do TEF e a observação, seguidas de discussão, de várias aulas de Pilates, foram efetuadas um conjunto de adaptações ao instrumento já existente, considerando as especificidades dos exercícios assim como os princípios da atividade de Pilates, verificando-se a necessidade de adequar e subdividir as categorias de instrução. Considerando que para manter a concentração, estimular a consciência corporal e realizar visualização mental é importante a instrução no decorrer da execução do exercício considerou-se pertinente existir um critério/dimensão denominado "Momento", que pretendia verificar em que momento a instrução era apresentada. Este critério/dimensão apresenta cinco categorias e nove subcategorias. Para além do "Momento" foi criada também o critério/dimensão "Conteúdo" que tinha como objetivo analisar o teor da instrução, englobando particularmente os princípios relacionados com a modalidade de Pilates. Este critério/dimensão é constituído por 10 categorias e oito subcategorias. Após realizada esta primeira proposta do SOIIFPILATES esta foi submetida a uma validação facial por outro grupo de especialistas.

\section{Fase 3: Validação facial do novo sistema de observação por especialistas (Experts)}

Baseado nas sugestões de Brewer e Jones (2002) e Prudente, Garganta e Anguera (2004) foi constituído um segundo painel de cinco especialistas, que nunca tivessem estado envolvidos neste processo anteriormente, a fim de avaliar se o SOIIF-PILATES possibilita codificar os comportamentos de instrução dos TEFs em aulas de Pilates e verificar se os critérios/dimensões e categorias/subcategorias foram devidamente definidas e relevantes para o referido contexto. Estes especialistas possuíam anos de experiência enquanto TEFs de aulas de grupo (inclusive em aulas de Pilates), formadores (ensino superior e técnico) e investigação nas áreas do Fitness, da pedagogia do desporto/ciências do desporto. Seguidamente, com base nos comentários e sugestões realizadas por este painel de especialistas, foi efetuada uma revisão dos critérios/dimensões e respetivas categorias/subcategorias de análise, procedendo-se assim a um segundo conjunto de adaptações e concluindo-se a versão final do SOIIF-PILATES. A versão final do sistema de observação SOIIFPILATES (tabela 1) apresenta dois critérios/dimensões de análise (momento e conteúdo), 15 categorias e 17 subcategorias.

Fase 4: Fiabilidade interobservadores em relação ao novo sistema de observação SOIIF-PILATES

Nesta fase foi testada a versão final do SOIIFPILATES, para verificar a objetividade das definições das categorias/subcategorias de comportamentos, segundo os procedimentos sugeridos por Brewer e Jones (2002), Gilbert, Trudel, Gaumond e Lorocque (1999) e Prudente et al. (2004). Esta fase permitiu assegurar que diferentes observadores codificavam os mesmos comportamentos observados nas mesmas categorias/subcategorias. Os procedimentos foram divididos de acordo com as seguintes fases: $1^{\text {a }}$ fase identificação das categorias/subcategorias do sistema; $2^{\mathrm{a}}$ fase - discussão do protocolo de observação; $3^{\mathrm{a}}$ fase - avaliação da aprendizagem das categorias/subcategorias; $4^{\mathrm{a}}$ fase - prática e aplicação do sistema de observação. Numa fase inicial, foi visionado um vídeo de uma aula de grupo de Pilates e realizada a respetiva codificação por ambos os observadores separadamente, não havendo acesso oral ou visual entre eles. Realizada a codificação foi testada a fiabilidade interobservadores a fim de verificar a existência de concordância entre observadores, através 
da medida de concordância Kappa de Cohen (Pestana \& Gageiro, 2005) sendo aceites valores de fiabilidade iguais ou superiores a $75 \%$.

\section{Fase 5: Fiabilidade intraobservador em relação ao novo sistema de observação}

Nesta fase foi testada a fidelidade intraobservador, do observador deste estudo, com o novo sistema de observação, para assegurar que existe fidelidade por teste/reteste relativamente ao novo instrumento e ao observador deste estudo, tal como recomendado por Brewer e Jones (2002). A fidelidade intraobservador foi realizada com o fim de verificar a existência de estabilidade temporal nas observações do próprio observador, efetuada em duas diferentes ocasiões. O intervalo adotado foi de uma semana entre cada observação. Para este procedimento foi utilizada a medida de concordância Kappa de Cohen (Pestana \& Gageiro, 2005), sendo aceites valores de fiabilidade iguais ou superiores a $75 \%$.

\section{Aplicação Piloto do SOIIF-PILATES}

Depois de desenvolvido o SOIIF-PILATES, foi efetuada a sua aplicação piloto, tal como sugere Santos et al. (2009). Após o consentimento informado e registado dos TEFs e alunos presentes na sessão, foram observados e codificados os comportamentos da instrução de 15 TEFs na atividade de Pilates. Estabeleceu-se como critérios para inclusão na amostra TEFs licenciados em desporto, experiência em aulas de grupo de Pilates superior a 5 anos e pelo menos uma formação em Pilates-Matwork (PilatesMat). Toda a amostra pertencia ao género feminino, com uma média de idade de 33.8 anos, experiência média enquanto TEF de 9.8 anos e enquanto TEF da modalidade de Pilates 7.5 anos. A média de aulas de Pilates por semana que as TEFs da amostra lecionavam era de 6.1 aulas.

Após a gravação dos vídeos em formato digital, estes foram observados e codificados os comportamentos utilizando o software Match Vision Studio Premium ${ }^{\circledR}$, de Perea, Alday e Castellano (2005). Posteriormente foi realizada uma análise para obter os valores absolutos de cada categoria/subcategoria do comportamento da instrução observada no TEF. Na codificação considerou-se que a aula foi iniciada quando o TEF o referiu através de indicação verbal ou colocou música. O término da sessão foi considerado quando o TEF o indicou através da indicação verbal ou terminou despedindo-se e/ou agradecendo a presença dos praticantes.

\section{Análise estatística}

Após a determinação do número de ocorrências de cada categoria/subcategoria em cada fase da aula e previamente ao tratamento estatístico propriamente dito, para cada aula, foi realizado o seguinte tratamento dos dados, utilizando o Excel: para cada fase prática da aula, foi verificado o n. $^{\circ}$ de exercícios realizados; para cada categoria/subcategoria a frequência relativa foi determinada dividindo o n. ${ }^{\circ}$ de ocorrências dessa categoria pelo $\mathrm{n}^{\circ}$ de exercícios, permitindo assim identificar qual a percentagem de exercícios em que essa categoria foi observada. Relativamente ao desenvolvimento do SOIIFPILATES foi utilizado o teste Kappa de Cohen $(K)$ para testar as fiabilidades interobservadores $\mathrm{e}$ intraobservador, tendo sido aceites valores iguais ou acima de $75 \%$, como já referido anteriormente. Para caracterizar a intervenção da instrução dos TEFs de Pilates, nas diversas fases da aula, para cada categoria/subcategoria, foi determinado a média e o desvio padrão, valor máximo e valor mínimo bem como a frequência absoluta relativa ao número de TEF'S que realizam aquela categoria/subcategoria. Para comparar as diferentes fases da aula, foi testado o pressuposto da normalidade, utilizando o teste de Shapiro-Wilk, para verificar se poderia ser utilizado o teste paramétrico Anova Medidas Repetidas. Não se tendo verificado normalidade nos três grupos em simultâneo, em nenhuma das categorias/subcategorias, utilizou-se o respetivo teste não paramétrico de Friedman. Optou-se por este teste, já que este se aplica quando existem três ou mais condições de emparelhamento. Para identificar entre que fases da aula (aquecimento, parte fundamental e alongamento/relaxamento) se verificaram diferenças significativas no total da instrução e entre as diferentes fases do exercício foi utilizado o teste post hoc não paramétrico de Dunn, que aplica a correção de Bonferroni ao nível da significância (Maroco, 2010). Todas as análises estatísticas foram realizadas utilizando o software SPSS 23.0.

Com o objetivo de calcular se o número de sessões observadas (15) permitia obter dados fiáveis foi realizada uma análise da generalização, utilizando o programa SAGT (Hernández-Mendo, BlancoVillaseñor, Pastrana, Morales-Sánchez \& RamosPérez, 2016). Os procedimentos para efetuar esta análise consistiram nos indicados por BlancoVillaseñor, Castellano, Hernández-Mendo, SánchezLópez e Usabiaga (2014), nomeadamente: 1) 
Tabela 1. Sistema de observação da instrução do instrutor de Fitness em aulas de Pilates (SOIIF-PILATES).

\begin{tabular}{|c|c|c|}
\hline $\begin{array}{l}\text { Critérios/ } \\
\text { Dimensões }\end{array}$ & Categorias & Subcategorias \\
\hline \multirow{11}{*}{$\begin{array}{l}\text { Momento: } \\
\text { Fase da aula } \\
\text { e/ou do } \\
\text { exercício } \\
\text { em que é } \\
\text { referida a } \\
\text { instrução. }\end{array}$} & Instrução no início da aula (IIA) & \\
\hline & Instrução no aquecimento (IA) & Instrução no aquecimento antes exercício (IA-A) \\
\hline & & Instrução no aquecimento durante exercício (IA-D) \\
\hline & & Instrução no aquecimento após exercício (IA-P) \\
\hline & Instrução na fase fundamental (IFF) & Instrução na fase fundamental antes exercício (IFF-A) \\
\hline & & Instrução na fase fundamental durante exercício (IFF-D) \\
\hline & & Instrução na fase fundamental após exercício (IFF-P) \\
\hline & Instrução no & Instrução no alongamento/relaxamento antes exercício (IAR-A) \\
\hline & alongamento/relaxamento (IAR) & Instrução no alongamento/relaxamento durante exercício (IAR-D) \\
\hline & & Instrução no alongamento/relaxamento após exercício (IAR-P): \\
\hline & Instrução no final da aula (IFA) & \\
\hline
\end{tabular}

$\begin{array}{ll}\text { Conteúdo: } & \text { Informa o contexto (IC): Instrutor } \\ \text { Teor da } & \text { informa acerca do âmbito da aula. }\end{array}$
instrução Liga os conteúdos (LC): Instrutor transmitida. relaciona conteúdos de diferentes aulas /própria aula.

Informa o objetivo (IO): Instrutor informa sobre qual (ais) o(s) objetivo(s) da aula ou do exercício.

Informa o Exercício (IE): Instrutor informa o nome do exercício.

Executa o Exercício (EE): Instrutor executa o exercício, total ou parcialmente, podendo utilizar praticante para tal. Esta execução pode ser antes, demonstrando-o, durante ou após os praticantes o realizarem

Informa as condições de realização (ICR): Instrutor informa acerca da disposição dos praticantes na sala e/ou da sua posição.

Informa as componentes críticas (ICC): Instrutor informa as componentes críticas do exercício.

Informa a visualização (IV): Instrutor informa para visualizarem mentalmente uma situação/sensação relacionados com o exercício. Informa o número de repetições (INR): Instrutor informa número de repetições do exercício.

Questiona (Q): Instrutor coloca questões.
Liga os conteúdos entre aulas (LC-EA): O instrutor relaciona conteúdos de diferentes aulas.

Liga os conteúdos da aula (LC-DA): O instrutor relaciona conteúdos da própria aula, nomeadamente entre exercícios.

Informa o objetivo da aula (IO-A): O instrutor informa sobre qual (ais) o(s) objetivo(s) da aula.

Informa o objetivo do exercício (IO-E): O instrutor informa sobre qual (ais) o(s) objetivo(s) do exercício.

Informa as componentes críticas Alinhamento postural (CC-AP): O instrutor informa o alinhamento postural correto.

Informa as componentes críticas Ativação do Core (CC-AC): O instrutor informa para ativar o core.

Informa as componentes críticas Respiração (CC-R): O instrutor informa como coordenar respiração com os exercícios.

Informa as componentes críticas Descrição do movimento (CC-DM): $\mathrm{O}$ instrutor informa quais os movimentos a realizar no exercício.

Correspondence to: Liliana Ricardo Ramos Dirección Postal: Av.Dr.Mário Soares, nº110, 2040-413 Rio Maior, Portugal

Email: lilianaramos@esdrm.ipsantarem.pt 
Cuadernos de Psicología del Deporte, vol. 21, 1, 225-241

Recibido: 03/06/2019

Aceptado: 02/09/2020
(C) Copyright 2018: Servicio de Publicaciones de la Universidad de Murcia Murcia (España) ISSN edición impresa: 1578-8423 ISSN edición web (http://revistas.um.es/cpd): 1989-5879

\section{Análise estatística}

Após a determinação do número de ocorrências de cada categoria/subcategoria em cada fase da aula e previamente ao tratamento estatístico propriamente dito, para cada aula, foi realizado o seguinte tratamento dos dados, utilizando o Excel: para cada fase prática da aula, foi verificado o n. $^{\circ}$ de exercícios realizados; para cada categoria/subcategoria a frequência relativa foi determinada dividindo o $n .^{\circ}$ de ocorrências dessa categoria pelo $n .^{\circ}$ de exercícios, permitindo assim identificar qual a percentagem de exercícios em que essa categoria foi observada. Relativamente ao desenvolvimento do SOIIFPILATES foi utilizado o teste Kappa de Cohen (K) para testar as fiabilidades interobservadores $\mathrm{e}$ intraobservador, tendo sido aceites valores iguais ou acima de $75 \%$, como já referido anteriormente. Para caracterizar a intervenção da instrução dos TEFs de Pilates, nas diversas fases da aula, para cada categoria/subcategoria, foi determinado a média e o desvio padrão, valor máximo e valor mínimo bem como a frequência absoluta relativa ao número de TEF'S que realizam aquela categoria/subcategoria. Para comparar as diferentes fases da aula, foi testado o pressuposto da normalidade, utilizando o teste de Shapiro-Wilk, para verificar se poderia ser utilizado o teste paramétrico Anova Medidas Repetidas. Não se tendo verificado normalidade nos três grupos em simultâneo, em nenhuma das categorias/subcategorias, utilizou-se o respetivo teste não paramétrico de Friedman. Optou-se por este teste, já que este se aplica quando existem três ou mais condições de emparelhamento. Para identificar entre que fases da aula (aquecimento, parte fundamental e alongamento/relaxamento) se verificaram diferenças significativas no total da instrução e entre as diferentes fases do exercício foi utilizado o teste post hoc não paramétrico de Dunn, que aplica a correção de Bonferroni ao nível da significância (Maroco, 2010). Todas as análises estatísticas foram realizadas utilizando o software SPSS 23.0.

Com o objetivo de calcular se o número de sessões observadas (15) permitia obter dados fiáveis foi realizada uma análise da generalização, utilizando o programa SAGT (Hernández-Mendo, BlancoVillaseñor, Pastrana, Morales-Sánchez \& RamosPérez, 2016). Os procedimentos para efetuar esta análise consistiram nos indicados por BlancoVillaseñor, Castellano, Hernández-Mendo, SánchezLópez e Usabiaga (2014), nomeadamente: 1)
Definição das facetas de estudo; 2) Análise da variação dos scores obtidos nas facetas do estudo; 3 ) Cálculo de componentes de erro; 4) Otimização dos coeficientes de Generalização.

\section{RESULTADOS}

No que diz respeito à fase 4 os valores de Kappa de Cohen para a fidelidade interobservador obtiveram $100 \%$ em todas as categorias e subcategorias (tabela 2 - $1^{\mathrm{a}}$ coluna). Relativamente à fase 5 , onde se testa a fiabilidade intraobservador, os valores de Kappa de Cohen variaram entre $79 \%$ e $100 \%$. (tabela 2 -

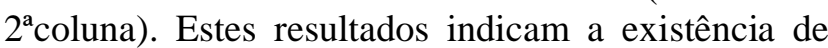
fiabilidade interobservadores e intraobservador, refletindo estabilidade temporal nas observações, entendimento e compreensão sobre a definição das dimensões e categorias/subcategorias que compõem o novo sistema de observação (SOIIF-PILATES).

Tabela 2. Fiabilidade interobservadores (Inter-O) e intraobservador (Intra-O) relativamente ao sistema de observação da instrução do instrutor de Fitness em Pilates (SOIIF-PILATES).

\begin{tabular}{|c|c|c|}
\hline $\begin{array}{l}\text { Categorias/ } \\
\text { Subcategorias }\end{array}$ & $\begin{array}{l}\text { Valor } K \\
\text { Inter-O } \\
\end{array}$ & $\begin{array}{l}\text { Valor } K \\
\text { Intra-O } \\
\end{array}$ \\
\hline Informa o contexto (IC) & $100 \%$ & $100 \%$ \\
\hline $\begin{array}{l}\text { Liga conteúdos entre aulas } \\
\text { (LCEA) }\end{array}$ & $100 \%$ & $100 \%$ \\
\hline Liga conteúdos da aula (LCDA) & $100 \%$ & $100 \%$ \\
\hline Informa objetivo da aula (IOA) & $100 \%$ & $100 \%$ \\
\hline $\begin{array}{l}\text { Informa o objetivo do exercício } \\
\text { (IOE) }\end{array}$ & $100 \%$ & $89 \%$ \\
\hline Informa o exercício (IE) & $100 \%$ & $100 \%$ \\
\hline Executa o exercício (EE) & $100 \%$ & $100 \%$ \\
\hline $\begin{array}{l}\text { Informa as condições de } \\
\text { realização (ICR) }\end{array}$ & $100 \%$ & $91 \%$ \\
\hline $\begin{array}{l}\text { Informa as componentes críticas } \\
\text { alinhamento postural (ICCAP) }\end{array}$ & $100 \%$ & $100 \%$ \\
\hline $\begin{array}{l}\text { Informa as componentes críticas } \\
\text { ativação do core (ICCAC) }\end{array}$ & $100 \%$ & $89 \%$ \\
\hline $\begin{array}{l}\text { Informa as componentes críticas } \\
\text { respiração (ICCR) }\end{array}$ & $100 \%$ & $100 \%$ \\
\hline $\begin{array}{l}\text { Informa as componentes críticas } \\
\text { descrição do movimento } \\
\text { (ICCDM) }\end{array}$ & $100 \%$ & $93 \%$ \\
\hline Informa a visualização (IV) & $100 \%$ & $100 \%$ \\
\hline $\begin{array}{l}\text { Informa o número de repetições } \\
\text { (INR) }\end{array}$ & $100 \%$ & $100 \%$ \\
\hline Questiona (Q) & $100 \%$ & $79 \%$ \\
\hline
\end{tabular}




\section{Desenvolvimento, Validação e Aplicação Piloto do SOIIF-Pilates}

Para a aplicação da Teoria da Generalização realizouse um desenho baseado em 2 facetas (Categorias e Sessões Observadas $=\mathrm{C} / \mathrm{S})$. A estimação dos componentes de variância foi realizada de forma aleatória infinita. Os resultados obtidos (tabela 3) mostram a maior variedade dos dados relacionada com a faceta Categorias (59.2\%), seguidas da faceta de interação entre Categorias e Sessões Observadas $(39.4 \%)$ e o restante para a faceta Sessões Observadas (1.4\%). Com estes resultados verifica-se (tabela 3 ) que as 15 sessões observadas no presente estudo permitem um coeficiente de generalização de 0.958 (valor relativo) e 0.956 (valor absoluto) que são considerados valores aceitáveis (Hernández-Mendo et al., 2016). Para um índice de generalização quase perfeito (perto da unidade) seriam necessárias observar 65 sessões, tal como exposto na tabela 3 .

Tabela 3. Estudo de decisão da análise de generalização para estimar o número de sessões.

\begin{tabular}{|c|c|c|c|c|}
\hline & $\begin{array}{l}15 \\
\text { sessões }\end{array}$ & $\begin{array}{l}25 \\
\text { sessões }\end{array}$ & $\begin{array}{l}50 \\
\text { sessões }\end{array}$ & $\begin{array}{l}65 \\
\text { sessões }\end{array}$ \\
\hline $\begin{array}{l}\text { Índice de } \\
\text { fiabilidade } \\
\text { (coef. G } \\
\text { relativo) }\end{array}$ & 0.958 & 0.974 & 0.987 & 0.990 \\
\hline $\begin{array}{l}\text { Índice de } \\
\text { generalidade } \\
\text { (coef. G } \\
\text { absoluto) }\end{array}$ & 0.956 & 0.973 & 0.986 & 0.990 \\
\hline
\end{tabular}

Decorrente da aplicação piloto do SOIIF-PILATES nas 15 aulas de Pilates analisadas verificou-se que, quanto à instrução no início da aula (tabela 4), apenas um TEF referiu a subcategoria ligação de conteúdos entre aulas, sendo que os restantes não apresentaram nenhuma instrução antes da fase prática. No final da aula, já depois do alongamento/relaxamento, foram observados cinco comportamentos de instrução nas categorias/subcategorias informa a componente crítica alinhamento postural, informa componente crítica ativação do core, informa componente crítica respiração, informa componente crítica descrição do movimento e por fim a categoria informa visualização $(\mathrm{M} \pm \mathrm{DP}=6.67 \pm 25.82 \%)$.
Tabela 4. Instrução no início e no final da aula

\begin{tabular}{|c|c|c|c|c|}
\hline & \multicolumn{4}{|c|}{ Instrução no início e final da aula } \\
\hline & Início da $\mathrm{Au}$ & & Final da Aula & \\
\hline Cat./Sub. & $\mathrm{M} \pm \mathrm{DP} \%$ & $\begin{array}{l}\text { FI- } \\
\mathrm{N}^{\mathrm{o}}\end{array}$ & $\mathrm{M} \pm \mathrm{DP} \%$ & $\begin{array}{l}\text { FI- } \\
\mathrm{N}^{\mathrm{o}}\end{array}$ \\
\hline IC & $0 \pm 0$ & 0 & $0 \pm 0$ & 0 \\
\hline LCEA & $6.67 \pm 25.82$ & 1 & $0 \pm 0$ & 0 \\
\hline LCDA & $0 \pm 0$ & 0 & $0 \pm 0$ & 0 \\
\hline IOA & $0 \pm 0$ & 0 & $0 \pm 0$ & 0 \\
\hline IOE & $0 \pm 0$ & 0 & $0 \pm 0$ & 0 \\
\hline IE & $0 \pm 0$ & 0 & $0 \pm 0$ & 0 \\
\hline $\mathbf{E E}$ & $0 \pm 0$ & 0 & $0 \pm 0$ & 0 \\
\hline ICR & $0 \pm 0$ & 0 & $0 \pm 0$ & 0 \\
\hline ICCAP & $0 \pm 0$ & 0 & $6.67 \pm 25.82$ & 1 \\
\hline ICCAC & $0 \pm 0$ & 0 & $6.67 \pm 25.82$ & 1 \\
\hline ICCR & $0 \pm 0$ & 0 & $6.67 \pm 25.82$ & 1 \\
\hline ICCDM & $0 \pm 0$ & 0 & $6.67 \pm 25.82$ & 1 \\
\hline IV & $0 \pm 0$ & 0 & $6.67 \pm 25.82$ & 1 \\
\hline INR & $0 \pm 0$ & 0 & $0 \pm 0$ & 0 \\
\hline $\mathbf{Q}$ & $0 \pm 0$ & 0 & $0 \pm 0$ & 0 \\
\hline
\end{tabular}

IC: Informa o contexto; LCEA: Liga os conteúdos entre aulas; LCDA: Liga os conteúdos da aula; IOA: Informa objetivo da aula; IOE: Informa objetivo exercício; IE: Informa nome do exercício; EE: Executa o exercício; ICR: Informa condições realização; ICCAP: Informa componentes críticas alinhamento postural; ICCAC: Informa componentes críticas ativação do core; ICCR: Informa componentes críticas respiração; ICCDM: Informa componentes críticas descrição do movimento; IV: Informa visualização; INR: Informa número de repetições; Q: Questiona; FI: Frequência Absoluta de Instrutoras;

Relativamente ao número de exercícios realizados em cada fase da aula este variou entre um a cinco exercícios no aquecimento $(\mathrm{M} \pm \mathrm{DP}=3.07 \pm 1.10 \%)$ seis a 22 exercícios na fase fundamental $(\mathrm{M} \pm \mathrm{DP}=11.47 \pm 4.37 \%)$ e um a três exercícios no alongamento/relaxamento $(\mathrm{M} \pm \mathrm{DP}=1.53 \pm \quad 0.74 \%)$. Durante o total da instrução no aquecimento (tabela 5), todas as instrutoras informaram acerca da componente crítica do alinhamento postural, embora não o tenham feito em todos os exercícios $(\mathrm{M} \pm \mathrm{DP}=76.89 \pm 25.27 \%)$. Relativamente às categorias mais verificadas no aquecimento em 14 dos TEFs observados estão presentes as categorias/subcategorias: informa a componente crítica descrição do movimento, informa as componentes críticas respiração e informa o número de repetições. Para além das categorias/subcategorias anteriormente referidas também as seguintes foram observadas na maioria dos exercícios realizados no aquecimento: executa o exercício e informa componente crítica ativação do core. Por fim, verifica-se que não houve registos de 
comportamento de instrução durante a fase de aquecimento na categoria/subcategoria informa $o$ contexto e informa o objetivo da aula. Relativamente aos comportamentos de instrução total na fase fundamental (tabela 5) foram verificados em todos os TEFs as categorias/subcategorias informa a componente crítica descrição do movimento, informa componente crítica respiração, informa componente crítica alinhamento postural, informa o número de repetições, informa componente crítica ativação do core, indica as condições de realização e a categoria executa o exercício. Em 14 TEFs foi observado a categoria informa visualização, em 13 o comportamento de instrução informa o exercício, em 12 a subcategoria informa objetivo do exercício e em 10 foi observado a categoria questiona. Por fim verifica-se que não houve registos de comportamentos de instrução durante a fase fundamental da aula na categoria informa o contexto e na subcategoria informa o objetivo da aula, tal como também foi verificado na fase do aquecimento. Relativamente à instrução total observada na parte do alongamento/relaxamento (tabela 5) a subcategoria da instrução mais observada (oito TEFs) na fase de alongamento/relaxamento foi a informa a componente crítica descrição do movimento seguida da categoria informa condições de realização, observada em sete TEFs. Na fase do alongamento/relaxamento total, existem categorias/subcategorias que nunca foram mencionadas, tais como: informa o contexto, ligação de conteúdo entre aulas, ligação de conteúdo da aula e informa o objetivo da aula. No que se refere à comparação entre o total da instrução nas diversas partes da aula verificou-se existir diferenças significativas nas categorias liga os conteúdos da aula (apenas diferenças entre as três fases no geral), informa o nome do exercício (apenas diferenças entre as três fases no geral), informa condições de realização (diferenças no geral e específicas entre o aquecimento e a fase fundamental), informa componentes críticas alinhamento postural, informa componentes críticas ativação do core, informa componentes críticas da respiração e informa componentes críticas descrição do movimento (todas as quatro categorias anteriores com diferenças no geral e específicas, entre o aquecimento e relaxamento/alongamento e fase fundamental e relaxamento/alongamento), informa visualização (com diferenças no geral e entre a fase fundamental e o relaxamento/alongamento), informa número de repetições (com diferenças no geral e específicas, entre o aquecimento e relaxamento/alongamento e fase fundamental e relaxamento/alongamento e a categoria questiona (com diferenças entre as três fases no geral).

No que concerne às comparações entre as fases do exercício (antes, durante e após o exercício) nas diferentes partes da aula (aquecimento, parte fundamental e alongamento/relaxamento) verificou-se (tabela 6) existirem diferenças entre fases em nove das 15 categorias/subcategorias no aquecimento, nomeadamente informa objetivo do exercício, informa exercício, executa exercício, informa componente crítica alinhamento postural, informa componente crítica ativação do core, informa componente crítica respiração, informa componente crítica descrição do movimento, informa visualização e informa número de repetições. No que se refere à parte fundamental, existiram diferenças em 11 das 15 categorias do sistema nas fases do exercício, nomeadamente informa objetivo exercício, informa exercício, executa exercício, informa componente crítica respiração, informa componente crítica alinhamento postural, informa componente crítica ativação do core, informa componente crítica respiração, informa componente crítica descrição do movimento, informa visualização, informa número de repetições e questiona, sendo que todas as categorias apresentaram diferenças de $p=$ 0.000 em relação às fases da aula. No que se refere à parte do alongamento/relaxamento existiram diferenças em quatro das 15 categorias relativas à fase do exercício, nomeadamente nas componentes críticas executa o exercício, informa componente crítica descrição do movimento, informa visualização e informa número de repetições.

Na tabela 6 estão também apresentadas onde se encontram as diferenças entre as fases da aula e do exercício. No aquecimento, três das categorias que apresentaram diferenças (informa objetivo do exercício, informa nome do exercício e informa visualização) foram identificadas apenas no geral das três categorias e não entre as mesmas. As restantes diferenças observadas no aquecimento, nomeadamente nas categorias executa o exercício, informa componentes críticas alinhamento postural, informa componentes críticas ativação do core, informa componentes críticas descrição do movimento e informa número de repetições apresentaram-se todas entre os momentos antes e durante o exercício bem como após e durante o exercício. Na fase fundamental, das 11 diferenças 


\section{Desenvolvimento, Validação e Aplicação Piloto do SOIIF-Pilates}

existentes nas categorias (tabela 6), nove apresentam diferenças entre antes e durante o exercício bem como após e durante o exercício. A categoria informa o nome do exercício apresenta diferenças antes e pós o exercício bem como pós e durante o exercício e a categoria informa condições de realização apresenta diferenças entre antes e pós o exercício bem como antes e durante o exercício. No relaxamento/alongamento todas as categorias que apresentaram diferenças fizeram-no apenas no geral das três fases.

Tabela 5. Instrução total nas diversas fases da aula (aquecimento, parte fundamental e relaxamento/alongamento) e comparação entre as mesmas.

\begin{tabular}{|c|c|c|c|c|c|c|c|}
\hline \multirow[b]{3}{*}{ Cat./Sub. } & \multicolumn{7}{|l|}{ Instrução } \\
\hline & \multicolumn{2}{|l|}{ Aquecimento } & \multicolumn{2}{|c|}{ Fase Fundamental } & \multicolumn{3}{|c|}{ Alongamento/Relaxamento } \\
\hline & $\mathrm{M} \pm \mathrm{DP} \%$ & $\mathrm{FI}^{-N^{\circ}}$ & $\mathrm{M} \pm \mathrm{DP} \%$ & FI-N $^{\circ}$ & $\mathrm{M} \pm \mathrm{DP} \%$ & FI-N ${ }^{o}$ & $\mathrm{P}$ \\
\hline IC & $0 \pm 0$ & 0 & $0 \pm 0$ & 0 & $0 \pm 0$ & 0 & 1.000 \\
\hline LCEA & $1.33 \pm 5.16$ & 1 & $0.74 \pm 2.86$ & 1 & $0 \pm 0$ & 0 & 0.607 \\
\hline LCDA & $2.22 \pm 8.60$ & 1 & $4.20 \pm 7.24$ & 5 & $0 \pm 0$ & 0 & $0.039 *$ \\
\hline IOA & $0 \pm 0$ & 0 & $0 \pm 0$ & 0 & $0 \pm 0$ & 0 & 1.000 \\
\hline IOE & $28.89 \pm 32.01$ & 8 & $40.70 \pm 35.80$ & 12 & $22.22 \pm 36.55$ & 5 & 0.074 \\
\hline IE & $32.33 \pm 29.80$ & 10 & $52.72 \pm 37.32$ & 13 & $20.00 \pm 36.84$ & 5 & $0.046 *$ \\
\hline EE & $76.44 \pm 36.59$ & 13 & $57.05 \pm 27.71$ & 15 & $33.33 \pm 44.99$ & 6 & 0.126 \\
\hline ICR & $7.89 \pm 14.15$ & 4 & $64.09 \pm 26.41$ & 15 & $38.89 \pm 47.00$ & 7 & $0.007 * 1$ \\
\hline ICCAP & $76.89 \pm 25.27$ & 15 & $80.85 \pm 27.01$ & 15 & $30.00 \pm 45.51$ & 5 & $0.005^{* 2,3}$ \\
\hline ICCAC & $61.44 \pm 34.15$ & 13 & $67.78 \pm 33.45$ & 15 & $20.00 \pm 41.40$ & 3 & $0.003^{* 2,3}$ \\
\hline ICCR & $80.89 \pm 29.45$ & 14 & $83.35 \pm 21.90$ & 15 & $32.22 \pm 44.75$ & 6 & $0.006^{* 2,3}$ \\
\hline ICCDM & $88.89 \pm 29.99$ & 14 & $88.38 \pm 23.87$ & 15 & $42.22 \pm 45.80$ & 8 & $0.003^{* 2,3}$ \\
\hline IV & $31.56 \pm 39.46$ & 7 & $42.29 \pm 33.88$ & 14 & $25.56 \pm 41.24$ & 5 & $0.017^{* 3}$ \\
\hline INR & $71.78 \pm 31.41$ & 14 & $78.29 \pm 27.05$ & 15 & $10.00 \pm 28.03$ & 2 & $0.002^{* 2,3}$ \\
\hline $\mathbf{Q}$ & $2.22 \pm 8.60$ & 1 & $8.67 \pm 8.40$ & 10 & $6.67 \pm 25.82$ & 1 & $0.002 *$ \\
\hline
\end{tabular}

IC: Informa o contexto; LCEA: Liga os conteúdos entre aulas; LCDA: Liga os conteúdos da aula; IOA: Informa objetivo da aula; IOE: Informa objetivo exercício; IE: Informa nome do exercício; EE: Executa o exercício; ICR: Informa condições realização; ICCAP: Informa componentes críticas alinhamento postural; ICCAC: Informa componentes críticas ativação do core; ICCR: Informa componentes críticas respiração; ICCDM: Informa componentes críticas descrição do movimento; IV: Informa visualização; INR: Informa número de repetições; Q: Questiona; FI: Frequência Absoluta de Instrutoras; * p $\leq$ 0,050; ${ }^{1}$ : Diferenças entre instrução no aquecimento e na fase fundamental; ${ }^{2}$ : Diferenças entre instrução no aquecimento e no relaxamento/alongamento ; ${ }^{3}$ : Diferenças entre instrução na fase fundamental e no relaxamento/alongamento.

Tabela 6. Instrução nas diversas partes da aula (aquecimento, parte fundamental e relaxamento/alongamento) antes, durante e após o exercício

\begin{tabular}{|c|c|c|c|c|c|c|c|}
\hline & \multicolumn{7}{|c|}{ Instrução no Aquecimento } \\
\hline & \multicolumn{2}{|c|}{ Antes do exercício } & \multicolumn{2}{|c|}{ Durante o exercício } & \multicolumn{3}{|c|}{ Após o exercício } \\
\hline & $\mathrm{M} \pm \mathrm{DP}$ & FI & $\mathrm{M} \pm \mathrm{DP}$ & FI & $\mathrm{M} \pm \mathrm{DP}$ & FI & $\mathrm{P}$ \\
\hline Cat./Sub. & $\%$ & N. ${ }^{\circ}$ & $\%$ & $\mathrm{~N}^{\circ}$ & $\%$ & N. ${ }^{\circ}$ & \\
\hline IC & $0 \pm 0$ & 0 & $0 \pm 0$ & 0 & $0 \pm 0$ & 0 & 1.000 \\
\hline LCEA & $0 \pm 0$ & 0 & $0 \pm 0$ & 0 & $0 \pm 0$ & 0 & 1.000 \\
\hline LCDA & $0 \pm 0$ & 0 & $2.22 \pm 8.60$ & 1 & $0 \pm 0$ & 0 & 0.368 \\
\hline IOA & $0 \pm 0$ & 0 & $0 \pm 0$ & 0 & $0 \pm 0$ & 0 & 1.000 \\
\hline IOE & $13.56 \pm 28.35$ & 4 & $18.89 \pm 25.37$ & 6 & $0 \pm 0$ & 0 & $0.026 *$ \\
\hline IE & $14.56 \pm 20.89$ & 6 & $18.22 \pm 28.19$ & 5 & $0 \pm 0$ & 0 & $0.043 *$ \\
\hline $\mathbf{E E}$ & $1.33 \pm 5.16$ & 1 & $68.11 \pm 35.85$ & 13 & $3.89 \pm 20.38$ & 2 & $0.000 * 2,3$ \\
\hline ICR & $3.00 \pm 7.97$ & 2 & $6.22 \pm 13.44$ & 3 & $0 \pm 0$ & 0 & 0.146 \\
\hline ICCAP & $2.22 \pm 8.60$ & 1 & $73.00 \pm 26.69$ & 14 & $3.89 \pm 10.38$ & 2 & $0.000 * 2,3$ \\
\hline ICCAC & $0 \pm 0$ & 0 & $57.56 \pm 33.33$ & 13 & $3.89 \pm 10.39$ & 2 & $0.000 * 2,3$ \\
\hline ICCR & $0 \pm 0$ & 0 & $77.00 \pm 28.56$ & 14 & $3.89 \pm 10.38$ & 2 & $0.000 * 2,3$ \\
\hline
\end{tabular}


Luís, T, Simões, V, Ramos, L, Franco, S.

\begin{tabular}{|c|c|c|c|c|c|c|c|}
\hline ICCDM & $0 \pm 0$ & 0 & $85.00 \pm 30.24$ & 14 & $3.89 \pm 10.38$ & 2 & $0.000 * 2,3$ \\
\hline IV & $1.33 \pm 5.16$ & 1 & $26.33 \pm 36.52$ & 7 & $3.89 \pm 10.38$ & 2 & $0.007 *$ \\
\hline INR & $2.22 \pm 8.60$ & 1 & $65.67 \pm 30.65$ & 14 & $6.11 \pm 17.94$ & 2 & $0.000 * 2,3$ \\
\hline \multirow[t]{2}{*}{$\mathbf{Q}$} & $0 \pm 0$ & 0 & $2.22 \pm 8.60$ & 1 & $0 \pm 0$ & 0 & 0.368 \\
\hline & \multicolumn{7}{|c|}{ Instrução na Fase Fundamental } \\
\hline IC & $0 \pm 0$ & 0 & $0 \pm 0$ & 0 & $0 \pm 0$ & 0 & 1.000 \\
\hline LCEA & $0.74 \pm 2.87$ & 1 & $0 \pm 0$ & 0 & $0 \pm 0$ & 0 & 0.368 \\
\hline LCDA & $2.04 \pm 6.51$ & 2 & $2.16 \pm 3.88$ & 4 & $0 \pm 0$ & 0 & 0.091 \\
\hline IOA & $0 \pm 0$ & 0 & $0 \pm 0$ & 0 & $0 \pm 0$ & 0 & 1.000 \\
\hline IOE & $12.28 \pm 20.79$ & 5 & $33.64 \pm 30.41$ & 12 & $0 \pm 0$ & 0 & $0.000 * 2,3$ \\
\hline IE & $28.85 \pm 29.57$ & 11 & $37.40 \pm 30.67$ & 12 & $1.20 \pm 3.44$ & 2 & $0.000 * 1,2$ \\
\hline EE & $13.69 \pm 19.31$ & 8 & $51.27 \pm 30.76$ & 14 & $0.67 \pm 2.58$ & 1 & $0.000 * 2,3$ \\
\hline ICR & $53.98 \pm 32.02$ & 14 & $11.68 \pm 22.55$ & 6 & $3.95 \pm 6.79$ & 5 & $0.000 * 1,3$ \\
\hline ICCAP & $0.61 \pm 2.35$ & 1 & $80.18 \pm 27.83$ & 15 & $2.25 \pm 5.02$ & 3 & $0.000 * 2,3$ \\
\hline ICCAC & $0.61 \pm 2.35$ & 1 & $67.11 \pm 4.13$ & 15 & $1.78 \pm 4.86$ & 2 & $0.000 * 2,3$ \\
\hline ICCR & $1.27 \pm 3.36$ & 2 & $82.69 \pm 22.48$ & 15 & $0 \pm 0$ & 0 & $0.000 * 2,3$ \\
\hline ICCDM & $0.61 \pm 2.35$ & 1 & $87.72 \pm 23.97$ & 15 & $0.67 \pm 2.58$ & 1 & $0.000 * 2,3$ \\
\hline IV & $1.27 \pm 3.36$ & 2 & $41.62 \pm 34.24$ & 14 & $1.11 \pm 4.30$ & 1 & $0.000 * 2,3$ \\
\hline INR & $0.91 \pm 2.55$ & 2 & $77.01 \pm 27.82$ & 15 & $1.64 \pm 3.59$ & 3 & $0.000 * 2,3$ \\
\hline \multirow[t]{2}{*}{$\mathbf{Q}$} & $0 \pm 0$ & 0 & $8.47 \pm 8.40$ & 10 & $0 \pm 0$ & 0 & $0.000 * 2,3$ \\
\hline & \multicolumn{7}{|c|}{ Instrução no alongamento/relaxamento } \\
\hline IC & $0 \pm 0$ & 0 & $0 \pm 0$ & 0 & $0 \pm 0$ & 0 & 1.000 \\
\hline LCEA & $0 \pm 0$ & 0 & $0 \pm 0$ & 0 & $0 \pm 0$ & 0 & 1.000 \\
\hline LCDA & $0 \pm 0$ & 0 & $0 \pm 0$ & 0 & $0 \pm 0$ & 0 & 1.000 \\
\hline IOA & $0 \pm 0$ & 0 & $0 \pm 0$ & 0 & $0 \pm 0$ & 0 & 1.000 \\
\hline IOE & $20 \pm 36.84$ & 4 & $8.89 \pm 26.63$ & 2 & $0 \pm 0$ & 0 & 0.091 \\
\hline IE & $10 \pm 28.03$ & 2 & $13.33 \pm 29.68$ & 3 & $0 \pm 0$ & 0 & 0.247 \\
\hline EE & $3.33 \pm 12.91$ & 1 & $30.00 \pm 45.51$ & 5 & $0 \pm 0$ & 0 & $0.015^{*}$ \\
\hline ICR & $25.56 \pm 41.24$ & 5 & $13.33 \pm 35.18$ & 2 & $0 \pm 0$ & 0 & 0.066 \\
\hline ICCAP & $0 \pm 0$ & 0 & $20 \pm 36.84$ & 4 & $10 \pm 28.03$ & 2 & 0.091 \\
\hline ICCAC & $0 \pm 0$ & 0 & $10 \pm 28.03$ & 2 & $10 \pm 28.03$ & 2 & 0.264 \\
\hline ICCR & $6.67 \pm 25.82$ & 1 & $25.56 \pm 41.24$ & 5 & $6.67 \pm 25.82$ & 1 & 0.069 \\
\hline ICCDM & $0 \pm 0$ & 0 & $38.89 \pm 43.03$ & 8 & $3.33 \pm 12.91$ & 1 & $0.001 *$ \\
\hline IV & $0 \pm 0$ & 0 & $25.56 \pm 41.24$ & 5 & $0 \pm 0$ & 0 & $0.007 *$ \\
\hline INR & $0 \pm 0$ & 0 & $13.33 \pm 29.68$ & 3 & $0 \pm 0$ & 0 & $0.050 *$ \\
\hline $\mathbf{Q}$ & $0 \pm 0$ & 0 & $6.67 \pm 25.82$ & 1 & $0 \pm 0$ & 0 & 0.368 \\
\hline
\end{tabular}

IC: Informa o contexto; LCEA: Liga os conteúdos entre aulas; LCDA: Liga os conteúdos da aula; IOA: Informa objetivo da aula; IOE: Informa objetivo exercício; IE: Informa nome do exercício; EE: Executa o exercício; ICR: Informa condições realização; ICCAP: Informa componentes críticas alinhamento postural; ICCAC: Informa componentes críticas ativação do core; ICCR: Informa componentes críticas respiração; ICCDM: Informa componentes críticas descrição do movimento; IV: Informa visualização; INR: Informa número de repetições; Q: Questiona; FI: Frequência Absoluta de Instrutoras; * p $\leq$ 0,050; ${ }^{1}$ : Diferenças entre antes e após o exercício; ${ }^{2}$ : Diferenças entre antes e durante o exercício; ${ }^{3}$ : Diferenças entre após e durante o exercício 
Cuadernos de Psicología del Deporte, vol. 21, 1, 225-241

Recibido: 03/06/2019

Aceptado: 02/09/2020
(C) Copyright 2018: Servicio de Publicaciones de la Universidad de Murcia Murcia (España) ISSN edición impresa: 1578-8423 ISSN edición web (http://revistas.um.es/cpd): 1989-5879

\section{DISCUSSÃO}

O presente estudo consistiu em desenvolver e validar um sistema de observação (SOIIF-PILATES) que permitisse analisar os comportamentos de instrução dos TEFs em aulas de Pilates. De acordo com alguns autores (Anguera \& Hernández-Mendo, 2013; Prudente et al., 2004; Sarmento, 2004) devem ser desenvolvidos instrumentos que estejam adequados e adaptados aos contextos específicos da sua aplicação. Para cumprir este requisito no processo de desenvolvimento e validação do SOIIF-PILATES, vários foram os procedimentos realizados, suportados por recomendações presentes na literatura (Anguera, Blanco, Losada \& Hernández-Mendo, 2000; Anguera, Blanco \& Losada, 2001; Brewer \& Jones, 2002; Hernández-Mendo, Blanco-Villaseñor, Pastrana \& Morales-Sánchez, 2016).

O SOIIF-AG foi desenvolvido e validado sob dois critérios/dimensões, o critério/dimensão "Momento" e "Conteúdo", apresentando validade, fiabilidade e generabilidade. A dimensão Momento é constituída por cinco categorias e nove subcategorias, permitindo enquadrar a ocasião em que decorre a instrução: início da aula; fase prática da aula (fases da aula: aquecimento, fase fundamental e alongamento/relaxamento; para cada exercício: antes, durante e após); fase final da aula. O critério/dimensão Conteúdo permite analisar o teor da instrução, sendo constituída por 10 categorias e oito subcategorias.

Posteriormente a versão desenvolvida e validada do SOIIF-PILATES foi aplicada a 15 TEFs, num estudo piloto. Os resultados demonstraram a importância do comportamento de instrução em contexto específico, uma vez que foram codificados um total de 333 comportamentos de instrução nas quinze aulas observadas. Segundo Kennedy e Yoke (2005) a instrução adequada é uma competência fundamental para ser um excelente instrutor. Franco et al. (2008) constataram que $60 \%$ dos comportamentos dos instrutores de ginástica localizada são de instrução. Um estudo desenvolvido por Fayh, Brodt, Souza e Loss (2018) concluiu que a existência de instrução no exercício de Pilates "long stretch" resultou numa maior ativação muscular dos músculos que constituem a "powerhouse" comparando com a realização do exercício sem instrução o que mais uma vez realça a importância deste comportamento pedagógico, em especial neste estudo, relacionado com um exercício da modalidade de Pilates. Atendendo às categorias/subcategorias mais observadas durante toda a aula podemos verificar que a maioria está relacionada com os princípios do Pilates, como a centralização, concentração, repetições dos exercícios, precisão, respiração e fluidez dos movimentos (Muscolino \& Cipriani, 2004; Isacowitz \& Clippinger, 2011), o que pode justificar a pertinência da sua utilização. No que concerne às comparações entre a instrução nas fases do exercício (antes, durante e após o exercício) nas diferentes partes da aula (aquecimento, parte fundamental e alongamento/relaxamento) verificaram-se diferenças entre nove, 11 e quatro categorias/subcategorias no aquecimento, parte fundamental e alongamento/relaxamento, respetivamente. $\mathrm{O}$ predomínio destas diferenças aconteceu, portanto, na parte fundamental da aula o que pode ser justificado pelo maior número de exercícios e duração realizado durante esta parte da aula. De realçar também que a maioria das diferenças significativas na instrução aconteceu, na comparação entre as fases do exercício, entre pós e durante o exercício bem como entre antes e durante o exercício (das 24 categorias onde existiram diferenças 15 foram deste género). Parece ser durante a realização do exercício que os TEF's privilegiam a realização de instrução, sendo que, quando se verificam diferenças entre as fases do exercício, é nesta fase que existe maioritariamente instrução. Exceciona-se a categoria informação acerca das condições de realização que, pela sua natureza de explicação inicial, ocorre maioritariamente antes do exercício.

Na comparação entre a instrução total nas diferentes fases da aula, designadamente aquecimento, parte fundamental e alongamento/relaxamento existiram diferenças significativas entre as fases da aula em 10 das 15 categorias/subcategorias de instrução na aula de Pilates, o que pode ser justificado pela diferença de instrução que existem nas diferentes fases da aula e que exigem diferentes abordagens. $\mathrm{Na}$ análise mais pormenorizada entre estas diferenças verificou-se que a maioria (cinco das 10) ocorrem entre o aquecimento e o relaxamento/alongamento e a fase fundamental e o relaxamento/alongamento. Verifica-se também que estas diferenças significativas acontecem porque $o$ total da instrução no relaxamento/alongamento é sempre inferior em relação ao aquecimento e à parte fundamental, à exceção da categoria questiona, o que

Correspondence to: Liliana Ricardo Ramos Dirección Postal:

Email: lilianaramos@esdrm.ipsantarem.pt 


\section{Luís, T, Simões, V, Ramos, L, Franco, S.}

pode ser justificado por ser uma fase da aula em que o TEF tenta falar menos de forma a que os praticantes consigam relaxar e preparar-se para o fim da aula.

Sabemos que a metodologia observacional apresenta algumas limitações. Uma delas está relacionada com a presença da câmara na aula, que pode influenciar o comportamento dos intervenientes na sessão. Para tentar minimizar este efeito os TEFs e praticantes foram informados acerca do objetivo geral do estudo, mas não especificamente sobre o que iria ser estudado no comportamento do TEF. A câmara foi também colocada num local que embora permitisse gravar todos os comportamentos, não tivesse influência sobre o normal funcionamento da aula. Outra das limitações prende-se com a expetativa do observador, podendo ser influenciado pelas suas motivações e desejo de obter determinados resultados. Esta limitação tentou ser minimizada com a fiabilidade inter e intraobservador, que não serviu só como fase de desenvolvimento do sistema, mas também como verificação da consistência do observador.

\section{APLICAÇÕES PRÁTICAS}

$\mathrm{Na}$ sequência deste estudo espera-se ter dado um contributo ao nível do conhecimento científico da área da pedagogia do desporto, em particular no que diz respeito ao comportamento da instrução dos TEFs em aulas de Pilates. Espera-se também que a existência deste instrumento (SOIIF-PILATES) possa constituirse como uma ferramenta não só para a área da investigação como também para a área de aplicação profissional, permitindo aos TEFs, diretores técnicos de ginásios e demais profissionais da área, a utilização deste instrumento para auxílio na autoanálise e supervisão da instrução dos TEFs em aulas de Pilates. Em investigações futuras o SOIIF- PILATES poderá ser utilizado analisando o comportamento de instrução com os dois critérios/dimensões (Momento e a Conteúdo) com as categorias e as subcategorias aqui propostas ou por sua vez, podem ser utilizadas algumas das categorias/subcategorias dependendo da análise instrução que seja do interesse do utilizador, sendo que o instrumento permite que seja feita uma análise mais macro ou micro na análise do teor da instrução. Pretende-se também que o SOIIF-PILATES possa ser utilizado como um complemento à utilização de outras metodologias, permitindo auxiliar investigações que pretendam realizar uma visão que integre várias perspetivas acerca do comportamento de instrução dos TEFs em aulas de Pilates, como por exemplo através da utilização das metodologias tradicionalmente designadas por quantitativa e qualitativa, dando abertura à realização de investigações que privilegiam a utilização destas duas metodologias em complemento uma da outra ("mixedmethod research") como sugere Anguera, Camerino e Castañer (2012).

\section{REFERÊNCIAS}

1. Abreu, M. de, Santos, F.C., Nogueira, A.L., Zampieri, M.L., \& Bertoncello, D. (2020). How the Pilates Method Can Influence Sports Performance in Different Modalities. Lecturas: Educación Física y Deportes, 24(264), 139-152. https://doi.org/10.46642/efd.v25i264.1812

2. Alexandre, N., \& Coluci, M. (2011). Validade de conteúdo nos processos de construção e adaptação de instrumentos de medidas. Ciência \& Saúde Coletiva, 16(7), 3061-3068. https://doi.org/10.1590/s14138123201100080 $\underline{0006}$

3. Alves, S., Rodrigues, J., Castañer, M., Camerino, O., Sequeira, P., Carvalhinho, L., Simões, V., \& Franco, S. (2014). Validação e Desenvolvimento de um Sistema de Observação da Comunicação Cinésica do Instrutor de Fitness. Motricidade, 10(1), 7787.https://doi.org/10.6063/motricidade.10(1). 2638.

4. Alves, S., Rodrigues, J., Castañer. M., Camerino, O., Sequeira, P., Carvalhinho, L., Simões, V., \& Franco, S. (2013). Sistema de observação proxémica do instrutor de Fitness (SOPROXFITNESS): Desenvolvimento, validação e estudo piloto. Revista Iberoamericana de Psicología del Ejercicio y el Deporte, 8(2), 281-299.

5. Anguera, M. T. (2003). La observación. En C. Moreno (Ed.). Evaluación psicológica. Concepto, proceso y aplicación en las áreas del desarrollo y de la inteligencia. Madrid: Sanz y Torres.

6. Anguera, M. T., Blanco-Villaseñor, A., \& Losada, J. L. (2001). Diseños Observacionales. Cuestión Clave en el Proceso de la Metodología Observacional. Metodología de 


\section{Desenvolvimento, Validação e Aplicação Piloto do SOIIF-Pilates}

las Ciencias del Comportamiento, 3(2), 135160.

7. Anguera, M.T., Blanco-Villaseñor, A., Losada., \& Hernández-Mendo, A. (2000). La metodología observacional en el deporte: conceptos básicos. [Electronic Version]. Lecturas: Educación Física y Deportes, 5. http://www.efdeportes.com/efd24b/obs.htm

8. Anguera, M.T., \& Blanco-Villaseñor, A. (2003). Registro y codificación en el comportamiento deportivo. En A. Hernández-Mendo, A. (Coord.), Psicología del Deporte (Vol. 2). Metodología (p. 6-34). Buenos Aires: Efdeportes (www.efdeportes.com) [Reimpreso en A. Hernández-Mendo (Coord.) (2005). Psicología del Deporte, Vol. II, Metodología (pp. 33-66). Sevilla: Wanceulen].

9. Anguera, M.T., Camerino, O., \& Castañer, M. (2012). 1: Mixed methods procedures and designs for research on sport, physical education and dance. In Camerino, O., Castañer, M., \& Anguera, M.T. (Eds.). Mixed Methods Research in the Movement Sciences (pp. 3-27). Oxon: Routledge.

10. Anguera, M. T. \& Hernández-Mendo, A. (2013). La metodologia observacional en el âmbito del deporte. E-balonmano.com: Revista de Ciencias del Deporte, 9(3), 135-160. http://www.ebalonmano.com/ojs/index.php/r evista/index.

11. Anguera, M.T., Magnusson, M.S., \& Jonsson, G.K. (2007). Instrumentos no estándar. Avances en Medición, 5(1), 63-82.

12. Bem, B., Tavares, D., \& Vendrusculo, A. (2019). Efeito do Método Pilates na dor lombar: revisão integrativa. ConScientiae Saúde, jan/marc.2019, 18(1), 133-140. https://doi.org/10.5585/conssaude.v18n1.108 04

13. Blanco-Villaseñor, A., Castellano, J., HernándezMendo, A., Sánchez-López, C.R. \& Usabiaga, O. (2014). Aplicacíon de la TG en el deporte para el studio de la fiabilidade, validez y estimación de la muestra. Revista de Psicología del Deporte, 23(1), 131-137. https://www.redalyc.org/articulo.oa?id=2351/ 235129571014

14. Blanco-Villaseñor, A., Losada, L. \& Anguera, M. T. (2003). Data analysis techniques in observational designs applied to the environment-behavior relation. Medio Ambiente y Comportamiento Humano, 4, 111126.

15. Brewer, B., \& Jones, R. L. (2002). A five-stage process for establishing contextually valid systematic observation instruments: the case of rugby union. The Sport Pshychologist, 16(2), 138-159. https://doi.org/10.1123/tsp.16.2.138

16. Carreiro da Costa, F. (1998). O Sucesso pedagógico em educação física. Estudo das condições e factores de ensino-aprendizagem associados ao êxito numa unidade de ensino. Tese de Doutoramento, Instituto Superior de Educação Física. Universidade Técnica de Lisboa, Cruz Quebrada. Lisboa

17. Dias, I., Franco, S., Ramos, L., \& Simões, V. (2020). Desenvolvimento do Sistema de Observação do Clima de Aula em Aulas de Grupo de Fitness - Aplicação Piloto em Idosos. Cuadernos de Psicologia Del Deporte, 20(2), 112-127. https://doi.org/10.6018/cpd.382331

18. Fayh, A., Brodt, G., Souza, C., \& Loss, J. (2018). Pilates instruction affects stability and muscle recruitment during the long stretch exercise. Journal of Bodywork \& Movement Therapies, 22 (2018), 471-475. http://doi.org/10.1016/j.jbmt.2017.05.010

19. Filho, O., Queiroz, G., Santos, J., Santos, M. Oliveira, L. \& Farah, B. (2019). Efeitos do Pilates na qualidade do sono em adultos e idosos: uma revisão sistemática. Rev Bras Ativ Fis $\quad$ Saúde, 2019;24. http://doi.org/10.12820/rbafs.24e0080

20.Franco, S. \& Simões, V. (2017). Fitness professional's pedagogical intervention. European Journal for Exercise Professionals - Europe Active, 1(1), 29-38.

21. Franco, S., Mercê. C., \& Simões, V. (2015). Preferência dods Praticantes Acerca do Comportamento Pedagógico dos Instrutores de Zumba. Journal of Sport Pedagogy and Research, 1(6), 30-35.

22. Franco, S., Rodrigues, J., \& Balcells, M. (2008). Comportamento pedagógico dos instrutores das aulas de grupo de Fitness de localizada. Fitness \& Performence Journal, 7(4), 251263. https://doi.org/10.3900/fpj.7.4.251.p 


\section{Luís, T, Simões, V, Ramos, L, Franco, S.}

23. Franco, S., Rodrigues, J., \& Castañer, M. (2012). Case Study 6.3: The Behavior of Fitness Instructors and the Preferences and Satisfaction Levels of Users. In O. Camerino. M. Castañer \& M. T. Anguera (Eds.). Mixed Methods Research in the Movement Sciences (pp. 202-214). Oxon: Routledge.

24. Gilbert, W., Trudel, P., Gaumond, S., \& Larocque, L. (1999). Development and aplication of an instrument to analyse pedagogical content interventions of ice hockey coaches. Sociology of Sport Online, 2.

25. Hernández-Mendo, A., Blanco-Villaseñor, A., Pastrana, J.L., Morales-Sánchez, V., \& Ramos-Pérez, F.J. (2016). SAGT: Aplicación informática para análisis de generalizabilidad. Revista Iberoamericana de Psicología del Ejercicio y el Deporte, 11(1), 77-89.

26. Hernández-Mendo, A., Díaz Martínez, F. \& Morales-Sánchez, V. (2010). Construcción de una herramienta observacional para evaluar las conductas prosociales em las classes de educación física. Revista de Psicología del Deporte, 19(2), 305-318.

27. IHRSA. (2016). The IHRSA European Health Club Report: Size and Scope of the Fitness Industry. Boston, MA: IHRSA.

28. Isacowitz, R. \& Clippinger, K. (2011). Pilates Anotomy. Champaing: Human Kinetics.

29. Kennedy, C., \& Yoke. M. (2005). Methods of Group Exercise Instruction. EUA: Human Kinectics.

30. Maroco, J. (2010). Análise de equações estruturais: Fundamentos teóricos, software \& aplicações. PêroPinheiro: ReportNumber.

31. Mars, H. (1989). Observer reliability: Issues and procedures. In P.W. Darst. D. Zakrajsek \& V.H. Mancini (2 $2^{\text {a }}$ Eds.). In H. Kinetics (Ed.). Analyzing physical education and sport instruction (pp. 54-80). Champaign. Illinois.

32. Matos, A. (2011). Efeitos do método de Pilates em populações saudáveis. Doutoramento em Ciências do Desporto. Universidade de Trásos-Montes e Alto Douro. Vila Real.

33. Mercê, C. Franco, S. Alves, S., Campos, F., \& Simões, V. (2015). Preferências dos Praticantes de Indoor-Cycling. relativamente ao Comportamento Pedagógico do Instrutor. Revista da UIIPS: Congresso Investigação.
Inovação e Tecnologia: Novos Desafios Resumos, 2(1), 59.

34. Muscolino J.E., \& Cipriani, S. (2004). Pilates and the "powerhouse". Journal Bodyw Mov, 8(1), 15-24.

https://doi.org/10.1016/S13608592(03)00057 $\underline{-3}$

35. Oliveira, L., Pires-Oliveira, D., Oliveira, R., Stocco, M., Jassi, F., Silva, J. \& Oliveira, R. (2014). Efeitos do Pilates na resistência muscular, flexibilidade e equilíbrio de mulheres jovens. ConScientiae Saúde2014, 13(4),

533-540. https://doi.org/10.5585/conssaude.v13n4.502 $\underline{4}$

36. Papadimitriou, D.A., \& Karteroliotis, K. (2000). The service quality expectations in private sport and Fitness centers: A reexamination of the factor structure. Sport Marketing Quaterly, 9, 157-64.

37. Perea, A., Alday, L., \& Castellano, J. (2005). Software para la observación deportiva Match Vision Studio. España.

38. Pestana, M. H., \& Gageiro, J. N. (2005). Análise de Dados para Ciências Sociais - A Complementaridade do SPSS. Lisboa.

39. Potrac, P., Brewer, C. J., Jones, R., Armour, K., \& Hoff, J. (2000). Toward an Holistic Understanding of the Coaching Process. Quest, 52, 186-199.

40. Prudente, J., Garganta, J., \& Anguera, M. T. (2004). Desenho e validação de um sistema de observação no Andebol. Revista Portuguesa de Ciências do Desporto, 4(3), 49-65. https://doi.org/10.5628/rpcd.04.03.49

41. Rodrigues, F., Bento, T., Cid, L., Neiva, H., Teixeira, D., Moutão, J., Marinho, D.A., \& Monteiro, D. (2018). Can Interpersonal Behavior Influence the Persistence and Adherence to Psysical Exercise Practice in Adults? A Systematic Review. Frontiers in Psychology, 9:2141. https://doi.org/10.3389/fpsyg.2018.02141

42. Rodrigues, F., Neiva, H., Marinho, D.A., Mendes, P., Teixeira, D.S., Cid, L., \& Monteiro, D. (2019). Assessing Need Satisfaction and Frustration in Portuguese Exercise Instructors: scale validity, reliability and invariance betwen gender. Cuadernos de 


\section{Desenvolvimento, Validação e Aplicação Piloto do SOIIF-Pilates}

Psicologia del Deporte, 19(1), 223-240. https://doi.org/10.6018/cpd.347331

43. Rodrigues, J. (1997). Os treinadores de sucesso. Estudo da influência do objectivo dos treinos e do nível de prática dos atletas na actividade pedagógica do treinador de voleibol. Cruz Quebrada. Lisboa: Edições Faculdade Motricidade Humana.

44. Rodrigues, J. (2000). A Investigação da Competência Pedagógica dos Treinadores. In Formação de Treinadores Desportivos (pp. 49-69). Rio Maior: Centro de Edições da Escola Superior de Desporto de Rio Maior.

45. Rosa, J.P.P., Souza, A.A.L., Lima, G.H.O., Rodrigues, D.F., Lemos, V.A., Alves, E.S., Tufik, S., \& Mello, M. (2015). Motivational and evolutionary aspects of a physical exercise training program: a longitudinal study. Frontiers in Psychology, 6, 648. https://doi.org/10.3389/fpsyg.2015.00648

46. Santos, F. M., Fernandez, J., Oliveira, M. C., Leitão, C., Anguera, T., \& Campaniço, J. (2009). The pivot player in handball and patterns detection - Instrument. Motricidade, 5,29-36.

https://doi.org/10.6063/motricidade.5(3).193
47. Sarmento, P. (2004). Pedagogia do Desporto e Observação. Cruz Quebrada. Lisboa: Edições Faculdade de Motricidade Humana. ISBN: 972-735-114-X

48. Sarmento, P., Veiga, A. L., Rosado, A., Rodrigues, J., \& Ferreira, V. (1998). Pedagogia do Desporto: instrumentos de observação sistemática da Educação Física e Desporto. Cruz Quebrada. Lisboa: Edições Faculdade de Motricidade Humana.

49. Souza, B., Justo, L., Silva, D., Lazzareschi, L., \& Glória, I. (2019). Influência do Método Pilates no tratamento da dor lombar crónica inespecífica: ensaio clínico controlado, aleatorizado e duplo cego. Revista científica $U M C$. ISSN:2525-5250.

50. Vecchi, K., Minasi, L., \& Nora, F. (2015). Avaliação dos benefícios do Pilates no solo em mulheres com lombalgias na faixa etária de 40 a 60 anos. Revista Movimenta, 8(1), 3036.

51. Wells, C., Kolt, G. S., \& Bialocerkowski, A. (2012). Defining Pilates exercise: a systematic review. Complementary therapies in medicine, 20(4), 253-262. https://doi.org/10.1016/j.ctim.2012.02.005 